\title{
Study on factors determinant of satisfaction in the use of e-learning at Telekomunikasi Indonesia Tbk
}

\author{
Rozak Laksmana Abdulkadir \\ Faculty of Economics and Business (FEB), Telkom \\ University \\ Bandung, Indonesia \\ r.laksmana.a@gmail.com
}

\author{
Ade Irma Susanty \\ Faculty of Communication and Business (FKB), Telkom \\ University \\ Bandung, Indonesia \\ adeirma@telkomuniversity.ac.id
}

\begin{abstract}
Nowadays, e-Learning is one of the media that becomes the mainstay of several companies in Indonesia. Service coverage, speed, ease of measurement, effectiveness and efficiency are some of the reasons why e-Learning is thus expected to be the solution of delivery and media dissemination of knowledge and information for all corporate entities. The implementation of e-learning in Telkom Indonesia has a weakness just like in the education system in general, i.e. the completion of the educational process. One of the drawbacks of elearning that appears at Telkom Indonesia is a penetration level that has not been so encouraging. This study developed an integrated model with several sub variables such as: courses, technology, design, marketing, management support, organizational culture, real need, time to learn, support, mandatory usage and incentives.

This study wanted to find out the factors that have influenced the satisfaction of the implementation of e-Learning in this company. By knowing the influencing factors, it is expected that the implementation of the strategy is more precise and has a solid foundation for the development of the implementation.
\end{abstract}

Keywords-e-Learning; learning completion; learning penetration

\section{INTRODUCTION}

E-Learning as we know allows organizations to train and develop employees. The e-learning advantage like cost savings, learning flexibility, better retention, effective and easy to manage makes e-Learning become more popular in corporations which have challenges on geographies and resources limitation. The growth in information, communication and technology ICT) has rapidly changed the world. Telecommunication companies like Telkom Indonesia have to be adaptive with this business turbulence. According to this situation, the teaching style, learning, dissemination of information and knowledge on this company should be more effective, efficient, and fast to prepare and deliver flexible and easy accesses.

In Telkom Indonesia, e-learning has been implemented since the end of 2007 and an estimated 40.000 accesses to elearning happened every year. E-learning journey in Telkom could survive until now because of many reasons. The main reason is management support to use and acknowledgement of e-learning position in this company. Some other reasons such as system quality, system delivery up to helpdesk support cause e-learning in Telkom to keep running. With the condition, company have to know the actual situation and still need to make continuous improvement to continuously improve the quality of e-Learning that runs this. Therefore, the study of factors that affect critical success for e-Learning is important for many stakeholder groups. There are several factors need to be considered when developing and implementing for the success of e-leaning in Telkom.

\section{LITERATUR REVIEW}

\section{A. E-Learning}

In the learning method that we used to know, learning is usually done on the basis of attendance in class, listening to lectures, to conduct the exam. The development of technology exists to provide another alternative learning model developed at any time. The method which we are familiar with eLearning. Defining e-Learning in general is the use of technology (information and telecommunication) to deliver the learning process. With the utilization of this technology is meant to enhance the existing learning systems and providing new alternative model of communication students and instructors .Some excess utilization of this technology is not only used by the education community, but also for various reasons (efficiency, effectiveness, business coverage and to the utilization of dissemination information) is also used by corporations. Corporations want to utilize the advantages of eLearning for various reasons and thus certainly with academic institutions.

\section{B. Learner Satisfaction Factors}

Implementation of e-Learning, as well as the implementation of information systems would provide an option succeeds, fails or no progress. What criteria the implementation of a system of application is successful or unsuccessful of course we have to know, this is caused due to the implementation of a system involving no small cost. The cost ranges certainly depends also on how much the target 
user of the application system, the complexity of the application and how big the infrastructure involved.

As noted in [1-6], user satisfaction is one component that affect the successful implementation of information systems. By paying attention to these factors then if e-Learning is considered a product and services it is expected that the learner will continue to use and the use of e-Learning. Satisfaction can be described as a person's feelings of pleasure or disappointment resulting from comparing the performance of a product that is perceived (or results) with expectations.

Factors to determine criterias that will be effect on the implementation of a classification system will provide a factor into an important factor, ordinary and unimportant. The important factors which tend to be determined by the dominant factors affecting. By knowing the factors, the corporate focus to consider factors or variables that are important and indispensable.

Implementation of e-Learning in Telkom Indonesia, which has been running since the end of 2007 has not done a portrait on the position of the implementation of e-Learning. Can it be said successful or to determine factors (to be studied) in fact can not be said to be successful. This study was conducted to determine the actual position so that if the efforts of the management of e-Learning, the efforts is research-based effort, not trial and error. Continuous improvement is an effort that must be made by the corporation to achieve the vision and mission of the corporation measurement and others are deliberate, using specifications that anticipate your paper as one part of the entire proceedings, and not as an independent document. Please do not revise any of the current designations.

\section{METHOD}

The main purposes of this study were to specify the critical factors influencing learner satisfaction for e-Learning, in the context of Telkom Indonesia. The literatures were reviewed to determine items relevant to factors for e-Learning. The topics of interest were implementation, criteria and indicator for the success of e-Learning. Selected paper used as reference for this research. The methodology for this research were analysing and synthesizing the literature review.

\section{DISCUSSION}

Based on [7, 8], analysis can be made as follows : System design which also includes system quality, information quality and service quality, is the most dominant factor to be owned and be the primary determinant. System quality which also includes "easy-to-use", "user friendly", "stable", "secure", "fast" and "responsive" is the first impression that need to be made by the organizers e-learning so that users will be interested to learn back and back. What is needed in the quality system here is consistently and continuously improve the quality of its owned. Once again it concerns the first impression to be made. Information quality inside containing ranging from designing the layout of the web site, until the clarity of the information submitted to the information that is always up-to-date. Service quality will make the service is always ready when needed and contain those who have always qualified and have a passion in providing the service.

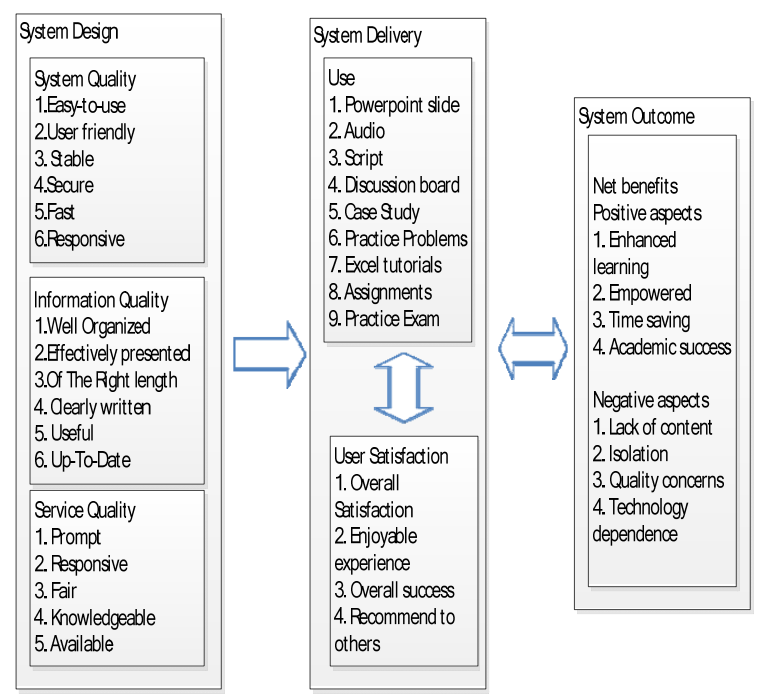

Figure 1 The e-Learning Success Model and sample metrics [8]

If the e-Learning is describes as hotel services, then the system design that can be considered as the willingness of infrastructure and hotel services are prepared to serve the guests, the delivery system can be considered as a content and satisfaction with his services. Delivery system that includes Use and User Satisfaction provide a powerful influence for users of e-Learning. Services discussion of fellow students, for example, is a service that not every operator can give because it involves a lot of things. If the service quality tends to the desired characteristics in the model of e-Learning on a replacement model of interaction between students and instructors, then the "use" we talk about the extent to the which the course elements are accessed. Closed with "satisfaction" in which we get the opinions of the students on e-learning. If his opinion lacking / not good then the learning system of this model will begin to be abandoned and will not increase the penetration to all employees, if good, then will deliver significant changes to all other users.

In net benefits we will get the overall benefits of elearning. Users will see it of course from two points of view, positive and negative. Positive to see an increase, empowered, time savings, and academic success, and for its Telkom certainly increase the efficiency and effectiveness of the learning process itself. Negative appear for the lack of contact, isolation, concern that the low quality and technology dependence is happening.

Referring to the reference outline is qualified models are created, some of the shortcomings of the two inputs is obtained including the helpdesk function which at times takes no place (call the helpdesk and no one pick it up, and it occurs at office hours). Increased knowledge and responsibilities needs to be improved because it results in user satisfaction levels will decrease. On the [9] conclusions, "in order to 
overcome technologies barriers, learners need to be provided with organizational support”. Support on that conclusions was talk about user training, technical support and also managerial encouragement to use e-Learning.

Another issue to be noted is about learning materials. Because of information technology business native, up-to-date should be considered to make the material is always current..

By reference [7], there are several success factors worthy of consideration into the factors that need to be taken into account in determining the successful implementation of eLearning. Factors such as Sufficient Users Training, Organization Commitment, Management Support, Technical Support, Positive attitude of users, Easy To Use Tools, Sufficient Training To Engineers, Sufficient e-Learning initiatives, Sufficient Manpower, availability of information on e-learning website and Support from other departments.

With refer to the reference, in general two things that still not good position. Support of the managers associated with helpdesk function and follow-up of the feedback that was never evaluated. Feedback provided by the user is never done the analysis and management never noticed that this could lead to a decrease in the level of user confidence. Feedback never processed, although this feedback can be a force for improvement.

Some studies make grouping factors to create a viewing angle more easily, and one good approach is based on [10] namely that produces Hexagonal e-Learning Assessment Model (HELAM) which divides the factors into six groups, Supportive, Social (learner perspective), Social (instructor attitudes), Technical (system quality), Technical (Information / content quality) and Technical (service quality).

Even this approach to the environment Telkom still has not fit with Telkom situation. With the HELAM, there is a dimension that does not comply with the conditions of Telkom, which is to the dimensions of the instructors, because at Telkom situation, instructor is not involved in the learning process.

On another reference [11], factors such as Learner, Instructor, Course, Technology, Design and environmental dimensions was defined as factors on dimensions and antecedents of perceived e-Learner satisfaction.. In a situation in Telkom Indonesia:

a. employees/learners are assumed to have been accustomed to using information technology, because since attendance, assignments, permission to leave, official correspondence to the calculation of the performance all have been using applications based information systems

b. using the model asynchronous, instructor / expert is only involved when developing a material and not involved in the interaction of the learning process.

c. test applied to all employees use the same matter.

This top list told to us that educational paradigm on elearning has shifted from the teacher-centric to a learnercentric model.

The other reference [12] was recommended several factors such as "must-have" factors and "nice-to-have" factors. The must-have factors include: useful and easy to use e-learning tools, marketing, management support, the right organizational culture, and the existence of a real need for the organization. The "nice to have" factors include: time to learn, support, mandatory learning, and incentives. Based on the research conclusions, a checklist of e-learning success factors is provided.

\section{CONCLUSIONS AND RECOMMENDATIONS}

The conclusions of this study are that first, e-learning strategy is not different from traditional/classical learning method because approach methodology is similar. Second, elearning methodology is more superior in some aspects that why so many corporations try to implement e-learning. Third, base on this research, each corporations have uniqueness and why critical success factors in one corporation may be different with another corporate.

The focus of e-learning is how learner have to enjoy to learn and more motivated to learn without interaction with instructor. The numerous efforts (factors) should be a concern that the successful implementation of e-learning, because should be gave more advantage and added value for the company.

In general, based on some research references obtained, Telkom has met some of the factors that are considered in the implementation of e-Learning. As conclusion special for Telkom for improving the quality of service there are several recommendations related to e-Learning in Telkom are:

1. The material is always up-to-date, because of developments in the telecommunications business is very fast its turbulence, so that the demands of e-Learning is also moving fast. Found material from the corporate logo alone is not in accordance with current corporate logo, so it is feared the content was too late to be modified according to current conditions.

2. Function helpdesk more care to always be there any time when needed, especially in the working hours of its existence. Dissatisfaction over the helpdesk service will trigger dissatisfaction with the overall e-Learning services that need to be very aware, if the e-Learning like better, then the service should be improved.

3. In the future, continued research needs to be done because of several dimensions that had been done by Telkom, such as marketing function, increased motivation through extrinsic motivation, approach to other internal organizations in Telkom to require employees to use eLearning, has not been included in the dimension to be explored. When an academic institution or a corporation to implement e-Learning, a holistic approach needs to be taken. Some things that have been done by Telkom entered as a considerations and it was done such as incentives for our employee whose attended on e-learning event. Combination of several factors that influence user satisfaction and valid in implementation at Telkom needs to be further investigated. This research necessary for the implementation of the strategy made by Telkom more precise and targeted. 
4. Based on the situation in the implementation of e-learning in Telkom, we recommend the 11 (eleven) sub-variables to be further investigated as a factor - determinants of satisfaction the use of e-learning. Eleventh sub-variable is the course, technology, design, marketing, management support, organizational culture, real need, time to learn, support, mandatory usage and incentives have been based on some research that became the reference of the foregoing,

\section{IMPLICATIONS/FUTURE WORK}

Cause of many reference put their factors based on their background and for Telkom condition still had a gap reason to receive one of them. Make a study to explore factors especially fit with Telkom condition.

\section{References}

[1] DeLone, William H and McLean, Ephraim R,” Information System Success : The Quest of Dependent Variabel", The Institut of Management Science", 1992, pp.60-95.

[2] DeLone, William H and McLean, Ephraim R, "The DeLone and cLean Model of Information Systems Success A Ten-Year Update", Journal of Management Information Systems, Vol. 19, No. 4, 2003, pp. 9-30.

[3] DeLone, William H and McLean, Ephraim R," Measuring e-Commerce Success: Applying the DeLone \& McLean Information Systems Success Model”, International Journal of Electronic Commerce, Vol. 9, No. 1 , 2004, pp. 31-47.
[4] Petter, Stacie, DeLone, William H and McLean, Ephraim R, "Measuring information systems success: models, dimensions, measures, and interrelationships", European Journal of Information Systems, pp 236 263, 2008

[5] Seddon, Peter B, "A Respesification and Extension of the DeLone and McLean Model of IS Success", Information System Research, VOl 8 No 3, 1997, pp $240-253$

[6] Caporarello, Leonardo and Sarchioni, Giacomo,"e-Learning: The Recipe for Success". Journal of e-Learning and Knowledge Society", v.10, 2014, pp $117-128$.

[7] Alhomod, Sami and Shafi, Mohd Mudasir, "Success factors of eLearning projects: a technical perspective",The Turkish Online Journal of Educational Technology, Saudi Arabia, vol. 12 Issues 2, pp. 247 253, April 2013.

[8] Holsapple, Clyde W and Lee-Post, Anita, "Defining, assessing, and promoting e-Learning success: an information systems perspective", Decision Sciences Journal of Innovative Education, volume 4 number 1 , pp 67 - 85, January 2006.

[9] Sawang, Sukanlaya. , Newton, Cameron., and Jamieson, Kieren,"Increasing learners'satisfaction/intention to adopt more elearning", Emerald, Vol 55 No.1, pp 83 - 105, 2013

[10] Ozkan, Sevgi. ,Koseler, Refika and Baykal, Zazife,”Evaluating learning management system: adopting of hexagonal e-learning assessment model in higher education", Emerald, pp 111 - 129, 17 Januari 2009.

[11] Sun, Pei-Chen, Tsai , Ray J, Finger, Glenn, Chen, Yueh-Yang \& Yeh Dowming, "What drives a successful e-Learning? An empirical investigation of the critical factors influencing learner satisfaction ", Science Direct, 2006.

[12] Sela, Eyal and Sivan, Y Yesha, "Enterprise E-Learning Success Factors: An Analysis of Practitioners' Perspective (with a Downturn ddendum)", Interdisciplinary Journal of E-Learning and Learning Objects Volume 5, 2009 , pp $225-343$. 